SCIDioc

\section{Assessment Of Different Types Of Malocclusion Using IOTN Index And Geographic Information System- A Cross-Sectional Observational Study}

Research Article

Dr. Bhagyalakshmi Avinash ${ }^{1 *}$, Dr. Balasubramanian S ${ }^{2}$, Dr. Ravikumar S3, Dr. Avinash BS

${ }^{1}$ Reader, Department of Orthodontics, JSS Dental College \& Hospital, S S Nagar, Mysore- 570015

${ }^{2}$ Director Research, JSSAHER, Mysore- 570015

${ }^{3}$ Assistant Professor, Division of Geoinformatics, Dept of Water \& Health, JSSAHER, S S Nagar, Mysore- 570015

${ }^{4}$ Reader, Department of Orthodontics, JSS Dental College \& Hospital, S S Nagar, Mysore- 570015

\title{
Abstract
}

Objective: Beauty is often considered as one of the pleasant aspects of life, and its influence is unavoidable. Dental appearance has a significant bearing on psychological well-being. A definite racial and geographical variation is observed in the northern and southern parts of India.

Methods: A cross-sectional Descriptive survey was planned in the school children of the Mysuru district. The sample size was 840 subjects. To assess the different types of malocclusion present, DHC of the IOTN was used. GIS mapping of prevalence and frequency of different malocclusions was done using Arc GIS software.

Results \& Discussion: Displacement of teeth was the most common malocclusion trait followed by an increase in Overjet among both Boys and girls in the present study with Missing teeth being the least prevalent. However, the difference in the distribution of these malocclusion traits between Boys and girls was not statistically significant $(p=0.48)$.

Conclusion: Among the various occlusal traits' displacement was the most common occlusal trait present both in girls and boys. $\square$ Even though displacement was the most common occlusal trait present, the recognition of its presence within the oral cavity was very low.

Keywords : Malocclusion; Orthodontic Treatment Needs; Iotn Index; Geographic Information System (Gis); Displacement; Overjet.

\section{Introduction}

Health is the extent of functional or metabolic regulation of a living body.Oral health connects with other health systems of the body. Malocclusion is a misalignment or incorrect relation between the teeth of the two dental arches when they approach each other as the jaws close. The term was coined by Edward Angle, the "father of modern orthodontics" [1]. Malocclusion varies from country to country and among different races.

India is a vast and a developing country. There are various epidemiological studies on malocclusion in India. Demographics play an important role in assessing the type of malocclusion. For example, Caucasians are known to have class III tendency and people of African origin tend to have bimaxillary protrusion. In India, even though there is a mix of different ethnic groups, the population in Kerala has tendency towards bimaxillary protru- sion.

Malocclusion features varies with different individuals and thus in different population, ethnicity, lifestyle, age and gender. Assessment of the quantification or the type of malocclusion gives scientific insight which helps in rendering optimal health to those in need. Various types of malocclusion are present in one's mouth. Knowing what type or types of malocclusion present will help us in quantifying the malocclusion.

Hence it is necessary to understand the different types of malocclusion present in a region.

A Geographic Information System (or GIS) is a system which is designed to capture, store, manipulate, analyse, manage and present spatial or geographical data. GIS technology is a powerful aid for public health profession as it provides data which can be used

*Corresponding Author

Dr. Bhagyalakshmi Avinash

Reader, Department of Orthodontics, JSS Dental College \& Hospital, S S Nagar, Mysore- 570015

Tel: 9902764937

E-mail: dr.bhagyalakshmia@jssuni.edu.in

Received: May 09, 2021

Accepted: July 09, 2021

Published: July 18, 2021

Citation: Bhagyalakshmi Avinash, Balasubramanian S, Ravikumar S, Avinash BS.Assessment Of Different Types Of Malocclusion Using Iotn Index And Geographic Information System- A Cross-Sectional Observational Study. Int J Dentistry Oral Sci. 2021;8(7):3279-3283. doi: http://dx.doi.org/10.19070/2377-8075-21000667

Copyright: Bhagyalakshmi Avinash ${ }^{\bullet}$ 2021. This is an open-access article distributed under the terms of the Creative Commons Attribution License, which permits unrestricted use, distribution and reproduction in any medium, provided the original author and source are credited. 
to communicate important facts about community. Also, GIS ties health to where people live.

The objectives of this study are,

1.To assess the different types of malocclusion present in 12-yearold school going children of Mysuru district,

2.To locate the different types of malocclusion present in 12-yearold school going children of Mysuru district using the Geographic Information System (GIS) Data.

3.To determine the most prevalent type of malocclusion present in 12-year-old school going children of Mysuru district.

\section{Materials And Methods}

\section{Study Design}

A cross-sectional descriptive survey was planned in the school children of Mysuru district. A prior permission from the Deputy Director for Public Instructions (DDPI) was obtained. Also, prior permission was obtained from the concerned school authorities.

\section{Study Setting}

The epidemiological survey was planned to be conducted in four taluks of Mysuru district. Three grades of school i.e., Government school, Private aided and Private Unaided school in the four taluks of Mysuru district were considered. The idea to include the three grades were to evaluate and compare the orthodontic treatment needs, awareness towards orthodontic need of the children of Mysuru district.

\section{Target Population}

School children around the age of 12 years were the target population.

\section{Sample And Sampling Technique}

Sample size was determined using sample size formula for prevalence study. The prevalence rate was fixed at $40 \%$ and relative precision was 0.12 . The sample size obtained was 840 subjects.

The sample size for the study was calculated using the formula,

$\mathrm{n}=\underline{\mathrm{Z} 2 \mathrm{P}(1-\mathrm{P})}$

$\mathrm{d} 2$

Where,

$\mathrm{n}=$ sample size,

$\mathrm{Z}=\mathrm{Z}$ statistic for a level of confidence,

$\mathrm{P}=$ expected prevalence and

$\mathrm{d}=$ precision

Two stage sampling was planned for the present study. In the first stage of sampling, four taluks were selected using simple random sampling by lottery method. Out of 840 subjects, 210 subjects were equally distributed to four taluks of Mysuru district. In the second stage of sampling, from each Taluk, schools were selected randomly to include 210 subjects by lottery method. In each school children in the age group of 12 years were chosen using the class Attendance register.

\section{Eligibility Criteria}

Inclusion Criteria

1.Children of 12 year old in the sampled schools.

2.Children who provided both informed consent from parents and informed assent to participate in the study.

\section{Exclusion Criteria}

1.History of previous orthodontic treatment.

2.Children undergoing orthodontic therapy.

3.Rampant caries

4.Any other craniofacial anomalies and syndromes.

\section{Ethical Considerations}

Prior permission to conduct the survey was taken from the Deputy Director Public Instructions (DDPI) and from the concerned school authorities. The survey protocol was reviewed and approved by the Institutional Review Board.Informed consent and Informed Assent were given a week prior to the parents of the child and the child. Only those children who provided both informed assent and consent were included in the survey.

\section{Data Collection}

To assess the different types of malocclusion, DHC of the IOTN was used. Among the 7 taluks of Mysuru district, 4 taluks were selected. The selected taluks were,

\section{1)Mysuru \\ 2)Nanjangud \\ 3)Hunsur \\ 4)T. Narasipura}

The examination was carried out under bright day light in the school premises. Sufficient sterilized instruments were carried out to the school on the day of examination.

\section{Data Entry}

At the end of each day of the survey, the data were entered to the personal computer by the investigator. The data was verified and were scrutinized at the end of each week for any wrong entries. Data were coded and entered excel sheet. To maintain the data quality rechecking and cross checking were done during data entry phase. $10 \%$ of the observations were randomly selected and cross-checked to detect any error and to validate the data entry. At the end of the survey, the data were scrutinized again and was handed over to the Statistician.

Statistical Analysis-Data were transformed into SPSS Windows version 16, where cleaning, coding, recoding, cross-checking, and processing and analysis were done by the statistician.

The following statistical tests were applied.

\author{
1.Frequency \\ 2.Descriptive \\ 3.Cross-tabulations (Contingency table analysis) \\ 4.Chi-square test.
}


All the statistical methods were carried out through the SPSS for Windows (version 16.0)

\section{GIS Mapping}

\section{The Base Map Creation}

The Base Map for the study is a district and taluk outer boundary layer that was created for Mysuru district and taluks of Myuru, Hunsur, Nanjangud and T-Narsipura. The individual taluk maps and the district map was merged to create the overall study area map. The information different types of malocclusion for each taluk and for Mysuru district was incorporated into the baseline map and the maps depicting the frequency of different types of malocclusion for each taluk and the Mysore district was created using Arc GIS software.The maps thus created provides a visual display of frequency of different types of malocclusion which helps in better planning of dental health services.

\section{Results}

\section{Descriptive Statistics}

Prevalence of malocclusion traits in relation to gender.

Among 409 Boys,

- $04(1 \%)$ had Missing teeth,

- $153(37.4 \%)$ had an increased Overjet,

- $35(8.6 \%)$ had Cross bite,
- $191(46.7 \%)$ had Displacement and

- $26(6.4 \%)$ had Overbite.

Among 436 girls,

- $03(0.7 \%)$ had Missing teeth,

- $184(42.2 \%)$ had an increased Overjet,

- $\quad 32(7.3 \%)$ had Cross bite,

- $198(50.9 \%)$ had displacement and

- $19(4.4 \%)$ had overbite.

Displacement of teeth was the most common malocclusion trait followed by an increase in Overjet among both Boys and girls in the present study with Missing teeth being the least prevalent. However, the difference in the distribution of these malocclusion traits between Boys and girls was not statistically significant ( $p$ $=0.48)$. This was evident even when a separate comparison was made among participants from Mysuru $(p=0.94)$, Nanjangud ( $p$ $=0.38)$, Hunsur $(\mathrm{p}=0.07)$ T- Narsipurtaluk $(\mathrm{p}=0.07)$ (Table 1, Figure 1).

\section{Mapping Of Different Traits Of Malocclusion}

GIS technology is a powerful aid for public health profession as it provides data which can be used to communicate important facts about community. Also, GIS ties health to where people live. In our survey, we have used GIS technology for locating the orthodontic treatment needs in the target population (Figure 2).

\section{Discussion}

In our study, $58.2 \%$ children presented with malocclusion. Dis-

Table 1: Prevalence of various malocclusion traits in relation to gender among participants in four taluks of Mysuru distric

\begin{tabular}{|c|c|c|c|c|c|c|c|c|c|c|c|c|c|c|}
\hline S1 No & $\begin{array}{l}\text { Taluk } \\
\text { name }\end{array}$ & \multicolumn{2}{|c|}{ Missing teeth } & \multicolumn{2}{|c|}{ Overjet } & \multicolumn{2}{|c|}{ Crossbite } & \multicolumn{2}{|c|}{ Displacement } & \multicolumn{2}{|c|}{ Overbite } & \multicolumn{2}{|c|}{ Total } & $\begin{array}{l}\text { Statistical } \\
\text { inference }\end{array}$ \\
\hline \multirow{2}{*}{ 1. 1} & & Boys & Girls & Boys & Girls & Boys & Girls & Boys & Girls & Boys & Girls & Boys & Girls & \\
\hline & & $\mathrm{N}(\%)$ & $\mathrm{N}(\%)$ & $\mathrm{N}(\%)$ & $\mathrm{N}(\%)$ & $\mathrm{N}(\%)$ & $\mathrm{N}(\%)$ & $\mathrm{N}(\%)$ & $\mathrm{N}(\%)$ & $\mathrm{N}(\%)$ & $\mathrm{N}(\%)$ & $\mathrm{N}(\%)$ & $\mathrm{N}(\%)$ & \\
\hline \multirow{3}{*}{2.} & \multirow{3}{*}{ Mysuru } & $\begin{array}{c}1 \\
(33.3)\end{array}$ & $\begin{array}{c}2 \\
(66.7)\end{array}$ & $\begin{array}{c}16 \\
(45.7)\end{array}$ & $\begin{array}{c}19 \\
(54.3)\end{array}$ & $\begin{array}{c}11 \\
(45.8)\end{array}$ & $\begin{array}{c}13 \\
(54.2)\end{array}$ & $\begin{array}{c}18 \\
(51.4)\end{array}$ & $\begin{array}{c}17 \\
(48.6)\end{array}$ & $\begin{array}{c}1 \\
(33.3)\end{array}$ & $\begin{array}{c}2 \\
(66.7)\end{array}$ & $\begin{array}{c}47 \\
(47.0)\end{array}$ & $\begin{array}{c}53 \\
(53.0)\end{array}$ & $\mathrm{X} 2: 0.76$ \\
\hline & & -2.1 & -3.8 & -34 & -35.8 & -23.4 & -24.5 & -38.3 & -32.1 & -2.1 & -3.8 & -100 & -100 & df: 4 \\
\hline & & & & & & & & & & & & & & p: 0.94 \\
\hline \multirow{3}{*}{3.} & \multirow{3}{*}{ Nanjangud } & $\begin{array}{c}1 \\
(50.0)\end{array}$ & $\begin{array}{c}1 \\
(50.0)\end{array}$ & $\begin{array}{c}74 \\
(54.4)\end{array}$ & $\begin{array}{c}62 \\
(45.6)\end{array}$ & $\begin{array}{c}10 \\
(71.4)\end{array}$ & $\begin{array}{c}4 \\
(28.6)\end{array}$ & $\begin{array}{c}72 \\
(47.7)\end{array}$ & $\begin{array}{c}79 \\
(52.3)\end{array}$ & $\begin{array}{c}3 \\
(37.5)\end{array}$ & $\begin{array}{c}5 \\
(62.5)\end{array}$ & $\begin{array}{c}160 \\
(51.4)\end{array}$ & $\begin{array}{c}151 \\
(48.6)\end{array}$ & $\mathrm{X} 2: 4.20$ \\
\hline & & -0.6 & -0.7 & -46.2 & -41.1 & -6.2 & -2.6 & -45 & -52.3 & -1.9 & -3.3 & -100 & -100 & df: 4 \\
\hline & & & & & & & & & & & & & & p: 0.38 \\
\hline \multirow{3}{*}{4.} & \multirow{3}{*}{ Hunsur } & $\begin{array}{c}2 \\
(100)\end{array}$ & $0(0)$ & $\begin{array}{c}38 \\
(45.2)\end{array}$ & $\begin{array}{c}46 \\
(54.8)\end{array}$ & $\begin{array}{c}10 \\
(47.6)\end{array}$ & $\begin{array}{c}11 \\
(52.4)\end{array}$ & $\begin{array}{c}40 \\
(60.6)\end{array}$ & $\begin{array}{c}26 \\
(39.4)\end{array}$ & $\begin{array}{c}10 \\
(76.9)\end{array}$ & $\begin{array}{c}3 \\
(23.1)\end{array}$ & $\begin{array}{c}100 \\
(53.8)\end{array}$ & $\begin{array}{c}86 \\
(46.2)\end{array}$ & X2: 8.54 \\
\hline & & -2 & 0 & -38 & -53.5 & -10 & -12.8 & -40 & -30.2 & -10 & -3.5 & -100 & -100 & df: 4 \\
\hline & & & & & & & & & & & & & & $\mathrm{p}: 0.07$ \\
\hline \multirow{3}{*}{5.} & \multirow{3}{*}{$\begin{array}{c}\text { T- } \\
\text { Narsipura }\end{array}$} & $0(0)$ & $0(0)$ & $\begin{array}{c}25 \\
(30.5)\end{array}$ & $\begin{array}{c}57 \\
(69.5)\end{array}$ & $\begin{array}{c}4 \\
(50.0)\end{array}$ & $\begin{array}{c}4 \\
(50.0)\end{array}$ & $\begin{array}{c}61 \\
(44.5)\end{array}$ & $\begin{array}{c}76 \\
(55.5)\end{array}$ & $\begin{array}{c}12 \\
(57.1)\end{array}$ & $\begin{array}{c}9 \\
(42.9)\end{array}$ & $\begin{array}{c}102 \\
(41.1)\end{array}$ & \multirow{3}{*}{$\begin{array}{c}146 \\
(58.9)\end{array}$} & X2: 6.97 \\
\hline & & 0 & 0 & -24.5 & -39 & -3.9 & -2.7 & -59.8 & -52.1 & -11.8 & -6.2 & -100 & & df: 4 \\
\hline & & & & & & & & & & & & & & p: 0.07 \\
\hline \multirow{3}{*}{6.} & \multirow{3}{*}{ Total } & $\begin{array}{c}4 \\
(57.1)\end{array}$ & $\begin{array}{c}3 \\
(42.9)\end{array}$ & $\begin{array}{c}153 \\
(45.4)\end{array}$ & $\begin{array}{c}184 \\
(54.6)\end{array}$ & $\begin{array}{c}35 \\
(52.2)\end{array}$ & $\begin{array}{c}32 \\
(47.8)\end{array}$ & $\begin{array}{c}191 \\
(49.1)\end{array}$ & $\begin{array}{c}198 \\
(50.9)\end{array}$ & $\begin{array}{c}26 \\
(57.8)\end{array}$ & $\begin{array}{c}19 \\
(42.2)\end{array}$ & $\begin{array}{c}409 \\
(48.4)\end{array}$ & $\begin{array}{c}436 \\
(51.6)\end{array}$ & X2: 3.49 \\
\hline & & & -0.7 & -37.4 & -42.2 & -8.6 & -7.3 & -46.7 & -45.4 & -6.4 & -4.4 & -100 & -100 & df: 4 \\
\hline & & & & & & & & & & & & & & p: 0.48 \\
\hline
\end{tabular}


Figure 1-Measure of agreement (kappa coefficient) between normative and perceptive orthodontic treatment need among participants with different malocclusion traits.

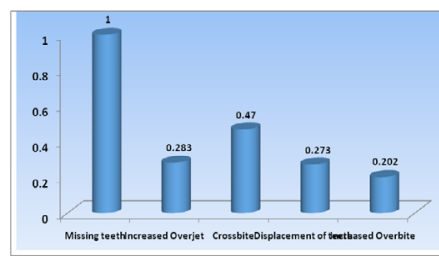

Figure 2- Prevalence of different traits of malocclusion in Mysuru taluk

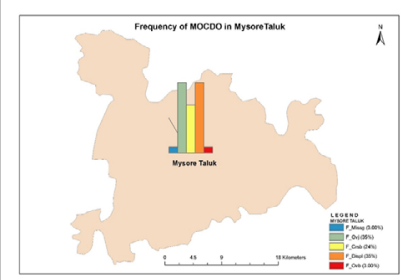

tribution of malocclusion in population showed that a maximum number of children i.e., $46 \%$ presented with Displacement, $39.9 \%$ presented with increased overjet, $7.9 \%$ presented with crossbite, $5.3 \%$ presented with increased overbite and $0.8 \%$ presented with missing teeth. The increased frequency of displacement and overjet in the study population can be explained by the fact that there is reduction in the jaw size with evolution and due to the transition of diet from coarse to soft. These results are in accordance with the results of other studies by other researchers [2]. Our finding that displacement is the most common feature (46\%) contrast with that of Tania Arshad et al [3] who found increased overjet to be the most common trait leading to malocclusion. A contributing factor for this difference is that Tania Arshad et al studied on orthodontic patients presenting to a clinic. Increased overjet is an obvious sign of malocclusion in one's mouth and patients presenting to clinics will be to some extent aware of their malocclusion status whereas patients presenting displacement may or may not be aware of their clinical malocclusion. The results of our study are also supported by a study done by Borzabadi- Farahani et al[4].

While applying statistical technique we found that there was no statistically significant difference between the type of malocclusion and gender. This is in accordance with the study done by Grand G et al, Kashif Aslam et al, Reddy et al, Onyeaso CO et al, Kaur $\mathrm{H}$ et al and Lauc $\mathrm{T}$ et al $[5,6,7,8,9,10]$.

Hence an exclusive analysis was done to know for which type of malocclusion there can be a strong agreement between the orthodontist and the child. A strong agreement was observed only for the missing teeth type of malocclusion (Figure 2). The consequence of missing tooth is self- imposing of dietary restrictions and thereby incurring health risks[11]. In addition, the presence of missing tooth has been associated with impaired chewing and inadequate nutrition[12]. Missing tooth may also lead to altered speech, ineffective mastication, loss of self-confidence, concern about appearance, and feeling of bereavement [13,14]. Since missing tooth has an enormous adverse impact on functional, social, and psychological well-being of the patients as well as on the remaining dentition. Most of the people with missing tooth would know its obvious presence and this explains why in our study we found a strong agreement between the orthodontist and the child for the malocclusion, missing tooth.

\section{Conclusion}

The Observations Recorded From Our Study Are As Follows

The Malocclusion Parameters As Recorded By The Iotn Index Is As Follows,

- Missing teeth- missing teeth is observed in $0.8 \%$ of the subjects.

- Overjet- overjet is observed in $39.9 \%$ of the subjects.

- Crossbite- crossbite is observed in $7.9 \%$ of the subjects.

- Displacement- displacement is observed in $46 \%$ of the subjects.

- Overbite- overbite is observed in $5.3 \%$ of the subjects.

\section{Limitations Of The Study}

- Children other than 12 years age are not included.

- Awareness of the parent towards orthodontic treatment is not included.

- It is only an observational study and no intervention is done.

\section{Clinical Relevance Of The Study}

While there have been several studies on assessment of different types of malocclusion, our study has thrown light on how we can utilise geographic information system (GIS) to identify the malocclusion. GIS ties health to where people live. With GIS technology, a dentist can know where exactly the malocclusion is existing and while doing so the dentist can localise his/her services to the exact geographic area. Linking GIS technology to health sector is a solution in attaining an ideal dentist: population ratio in rural as well as in urban sectors.

\section{References}

[1]. World Health Organization. Preamble to the Constitution of the World Health Organization as adopted by the International Health Conference, New York, 19-22 June, 1946; signed on 22 July 1946 by the representatives of 61 States (Official Records of the World Health Organization, no. 2, p. 100) and entered into force on 7 April 1948. http://www. who. int/governance/eb/who_constitution_en. pdf. 1948.

[2]. Kharbanda OP. What is the prevalence of malocclusion in India? Do we know Orthodontic treatment needs of our country. J Indian Orthod Soc. 1999;32(2):33-41. 
[3]. Siddiqui TA, Shaikh A, Fida M. Agreement between orthodontist and patient perception using Index of Orthodontic Treatment Need. Saudi Dent J. 2014 Oct;26(4):156-65. Pubmed PMID: 25382948.

[4]. Borzabadi-Farahani A, Borzabadi-Farahani A, Eslamipour F. Orthodontic treatment needs in an urban Iranian population, an epidemiological study of 11-14 year old children. Eur J Paediatr Dent. 2009 Jun;10(2):69-74. Pubmed PMID: 19566372.

[5]. Grando G, Young AA, Vedovello Filho M, Vedovello SA, Ramirez-Yańez GO. Prevalence of malocclusions in a young Brazilian population. Int J Orthod Milwaukee. 2008 Summer;19(2):13-6. Pubmed PMID: 18686678

[6]. Nadim R, Aslam K, Rizwan S. Frequency of malocclusion among 12-15 years old school children in three sectors of Karachi. Pakistan Oral and Dental Journal. 2014 Sep 30;34(3).

[7]. Reddy ER, Manjula M, Sreelakshmi N, Rani ST, Aduri R, Patil BD. Prevalence of Malocclusion among 6 to 10 Year old Nalgonda School Children. J Int Oral Health. 2013 Dec;5(6):49-54. Epub 2013 Dec 26. Pubmed PMID: 24453444.

[8]. Onyeaso CO. Prevalence of malocclusion among adolescents in Ibadan, $\mathrm{Ni}$ geria. Am J Orthod Dentofacial Orthop. 2004 Nov;126(5):604-7. Pubmed
PMID: 15520693.

[9]. Kaur H, Pavithra US, Abraham R. Prevalence of malocclusion among adolescents in South Indian population. J Int Soc Prev Community Dent. 2013 Jul;3(2):97-102. Pubmed PMID: 24778988.

[10]. Lauc T. Orofacial analysis on the Adriatic islands: an epidemiological study of malocclusions on Hvar Island. Eur J Orthod. 2003 Jun;25(3):273-8. Pubmed PMID: 12831217.

[11]. Chauncey HH, Muench ME, Kapur KK, Wayler AH. The effect of the loss of teeth on diet and nutrition. Int Dent J. 1984 Jun;34(2):98-104. Pubmed PMID: 6588038.

[12]. Wu Y, Pang Z, Zhang D, Jiang W, Wang S, Li S, et al. A cross-sectional analysis of age and sex patterns in grip strength, tooth loss, near vision and hearing levels in Chinese aged 50-74 years. Arch Gerontol Geriatr. 2012 Mar-Apr;54(2):e213-20. Pubmed PMID: 21893354.

[13]. Burt BA, Eklund SA. Dentistry, dental practice, and the community-Ebook. Elsevier Health Sciences; 2005 Mar 1.

[14]. Krall EA, Garvey AJ, Garcia RI. Alveolar bone loss and tooth loss in male cigar and pipe smokers. J Am Dent Assoc. 1999 Jan;130(1):57-64. Pubmed PMID: 9919032. 